\title{
ADVANTAGES OF THE PARABOLIC EXPRESSION OF HEIGHT-DIAMETER RELATIONSHIPS ${ }^{1}$

\author{
BY J. W. KER ${ }^{2}$ and J. H. G. SMITH ${ }^{3}$
}

\section{$A B S T R A C T$}

Six methods of determining parabolic expressions of height-diameter relationships have been compared with two other mathematical methods of curve-fitting. It has been shown that short-cut approximations of the leastsquares solution of the parabola are accurate; they are useful because of their ease of application and good conformance with the true height-diameter relationship. In this example the short-cut approximation methods have provided more desirable solutions than those secured using Henricksen's semi-logarithmic method, Stoffel's log-log method, H. A. Meyer's exponential solution of the parabola, and Staebler's precise least-squares solution of the parabolic equation with " $a$ " variable. Three short-cut methods for calculating parabolic curves have been illustrated with data from the Campus Forest of the University of British Columbia. Special uses of the parabolic relationship have been described. Construction of site-class volume tables has been demonstrated with data for a number of commercial tree species in the Arrow Lakes District of British Columbia. The short-cut methods of determining parabolic heightdiameter relationships have so many advantages that they are recommended for general use in forest inventory and for permanent plot studies.

The volume of wood in a forest stand is commonly estimated by means of a double sampling procedure in which a stand table, derived from cruise tallies, is converted into stand volume per acre by means of tree volumes derived from a standard tree-volume table. The stand table is an expression of the average number of trees per acre, by species and diameter (d.b.h.) classes, and is derived from the samples taken within a given sampling unit. The intensity of the cruise is the percentage relationship of sample area, on which the diameters of all trees are measured or estimated, to the total area of the sampling unit.

A standard volume table lists, for a given species, the average volume of trees in various d.b.h. and total-height classes. Before such a table can be used to determine the volume of wood represented by a given stand table, knowledge of the relationship between total height and d.b.h. is essential. For cruising or inventory it is thus necessary to take a sub-sample, i.e., to measure or estimate the height of representative trees of known d.b.h. throughout the range of diameter.

To date the majority of height-diameter curves have been drawn free-hand. This is a simple, rapid, graphical method that provides, if used with care, accurate results with a minimum of time and facilities. On the other hand it it a highly subjective method that, even for a given set of data, will never yield

\footnotetext{
${ }^{2}$ Resenrch Paper No. 10, Faculty of Forestry, University of British Columbia

2 Associate Professor, Faculty of Forestry, University of British Columbia. Biographical reference For. Chron. 29:367

${ }^{3}$ Assistant Professor, Faculty of Forestry, University of British Columbia. Biographical reference For. Chron. 30(2):197.

Received for publication January 18, 1955
} 
of the B.C. Forest Service showed that the parabolic curve was a reasonable expression of the vast majority of height-diameter relationships, but a more comprehensive basis was desirable for the estimation of the parameters $b$ and $c$. Consequently, Alexander (1945) used sample heights such as those commonly measured throughout the entire range of d.b.h. on permanent sample plots. To solve for the parameters, Alexander adopted a short-cut method of least squares described by Bruce and Schumacher (1950, pp. 199-200). In applying this method to measurements taken on permanent sample plots by the B.C. Forest Service over the past 30 years, Ker noted a defect arising from the preponderance of small-diameter trees that had been measured on many plots. Maintaining a balance in number of trees in the smaller- and larger-diameter groups, as prescribed in the short-cut method, leads to a poor curve-fit at the upper, and more important, end of the diameter range if there is pronounced skewness. This defect can be remedied by dividing the trees into two groups above and below the mid-range of diameter, i.e., at the diameter corresponding to the mean of the smallest and largest sample trees. In obtaining height measurements in the future, particular care can be taken to select sample trees that are distributed reasonably uniformly over the range of diameter. Recommended methods of calculation are illustrated with data from Permanent Sample Plot No. 1 on the Campus Forest of the University of British Columbia at Vancouver, B.C.

Good approximations of the least-squares solution of the parabolic heightdiameter equation may be obtained by the following methods.

\section{Method I}

1. The data are sorted into two groups on the basis of the mid-range of diameter, i.e., the diameter corresponding to the mean of the smallest and largest sample trees.

2. The constant $a=4.5$ feet is subtracted from each tree height. $(\mathrm{H}-4.5)$.

3. Each reduced tree height is divided by its corresponding diameter, thereby producing a linear transformation of height. (H-4.5)/D.

4. Diameter (D) and $(\mathrm{H}-4.5) / \mathrm{D}$ are totalled for all the trees in each group.

5. The totals for each group are substituted in the following equations which are then solved smiultaneously for the constants $\mathrm{b}$ and $\mathrm{c}$ :

$$
\text { (i) } \begin{aligned}
S_{1}\left(\frac{H-4.5}{D}\right) & =n_{1} b-S_{1} \text { (D) } c \\
\text { (ii) } S_{2}\left(\frac{H-4.5}{D}\right) & =n_{2} b-S_{2}(D) c
\end{aligned}
$$

6. With $\mathrm{b}$ and $\mathrm{c}$ determined, average maximum height, $\mathrm{Hmax}=4.5+$ $b^{2} / 4 c$, the corresponding diameter, $D_{H m}=b / 2 c$, and the estimated height $(H)$ for a tree of any diameter less than $D_{\mathrm{Hm}}$ are calculated from the equation $\mathrm{H}=4.5+\mathrm{bD}-\mathrm{cD}^{2}$.

The application of this method is illustrated in the following example with data collected on Permanent Sample Plot No. 1, Campus Forest, University of B.C. 


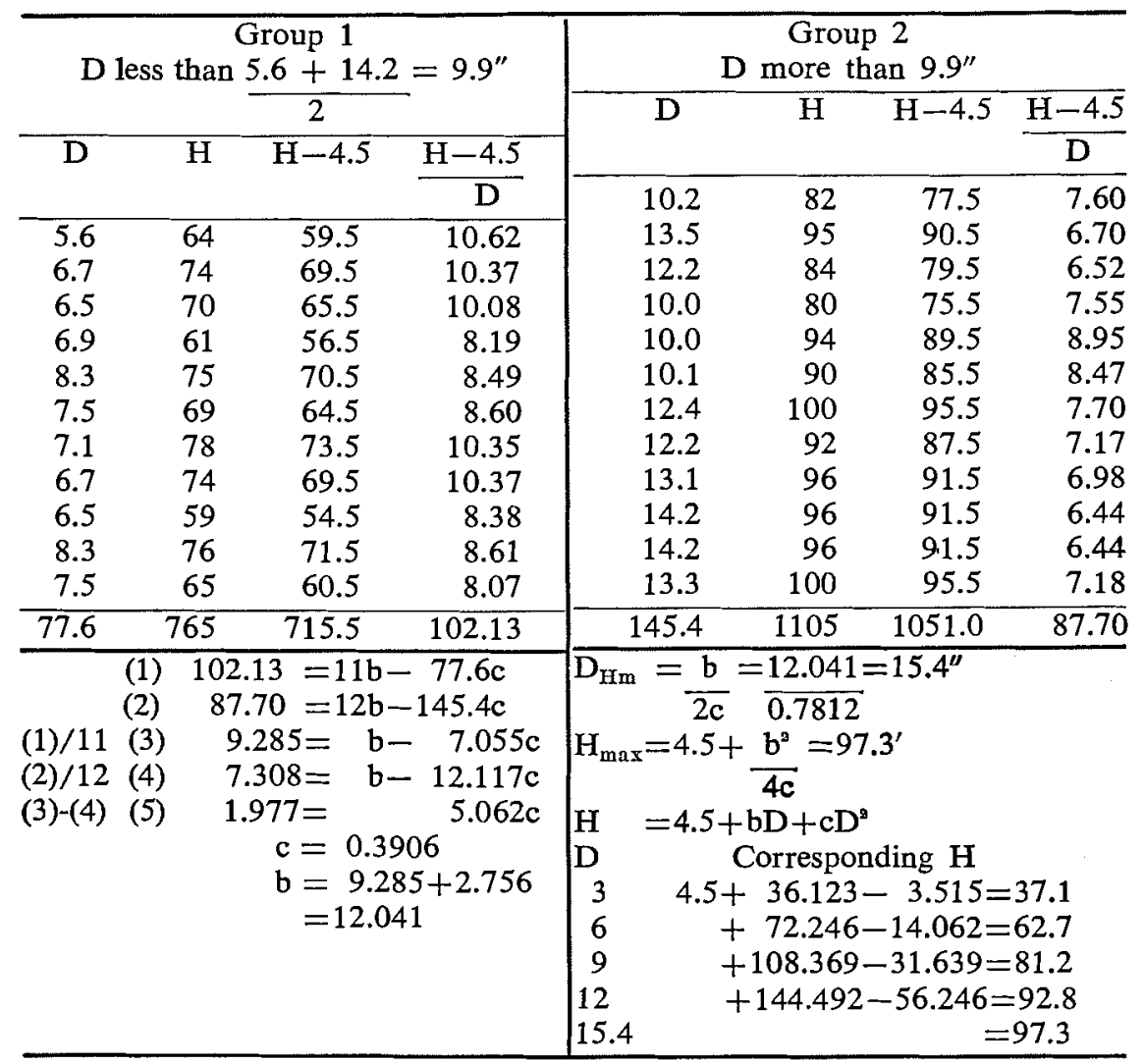

\section{Method II}

The short time required for the above procedure may be reduced further by a modification suggested by $F$. W. Waldie who found that $S(H)-n(4.5)$ is approximately equal to $\mathrm{S}(\mathrm{H}-4.5)$ in many cases.

S(D)

$$
\text { D }
$$

For the above data the estimated values of the average $\mathrm{H}-4.5$ are, for groups 1 and 2 respectively:
(1) $\frac{765-49.5}{77.6}=9.220$
(2) $\frac{1105-54}{145.4}=7.228$

These estimates may be used in place of 9.285 and 7.308 in equations (3) and (4) above to give:

$$
c=0.3935 ; \mathrm{b}=11.996 ; \mathrm{D}_{\mathrm{Hm}}=15.24^{\prime \prime} ; \mathrm{H}_{\max }=95.8^{\prime}
$$




\section{Method III}

Another simplification of Method I has been used by J. H. G. Smith. This is a graphical solution of the averages secured from groups 1 and 2 by Methods I or II, but preferably by Method I. On ordinary graph paper, the averages of $\mathrm{H}-4.5$ for each group are plotted over the corresponding D's. A $\frac{\mathrm{D}}{\mathrm{D}}$

straight line is then drawn through the two averages and projected to the left to correspond with $\mathrm{D}=0^{\prime \prime}$ and to the right to the maximum diameter required. Values of $\mathrm{H}-4.5$ corresponding to any required $\mathrm{D}$ may be read directly from this line in order to plot the curve of $H$ on $D$. The accuracy of plotting and calculation may be checked by determining the averages of $\mathrm{H}-4.5$

and $\mathrm{D}$ from all the data. These averages represent a point that must lie precisely on the straight line between the first two plotted points. Since the line represents the equation $\frac{\mathrm{H}-4.5}{\mathrm{D}}=\mathrm{b}-\mathrm{cD}, \mathrm{b}=\frac{\mathrm{H}-4.5}{\mathrm{D}}$ where $\mathrm{D}$ is 0 , and $\mathrm{c}=$ $b$-the $H-4.5$ for $D=10$. The results secured by Method III differ slightly $\frac{\frac{\mathrm{H}-4.5}{\mathrm{D}} \text { for } \mathrm{D}=10}{10}$

from those of Methods I or II but are surprisingly accurate and convenient to determine.

\section{a Comparison of Mathematical Methods}

Methods I, II, and III were compared with the more promising methods of curve-fitting employed in Europe and the United States. Method IV is a short-cut least-squares solution of the relationship suggested by Stoffels (1950): $\log H=a+b \log D$. Method $V$ is a least-squares solution of the form suggested by Henricksen (1950): $\mathrm{H}=\mathrm{a}+\mathrm{b} \log \mathrm{D}$. Method VI is the leastsquares solution of the parabolic equation: $\mathrm{H}=4.5+\mathrm{bD}-\mathrm{cD}^{2}$. Method VII is the approximation of the least-squares solution to the exponential equation proposed by $H$. A. Meyer (1940): $Y_{c}=4.5+h(1-e-a x)$, where $Y_{c}$ is the curve height for any $\mathrm{d}=\mathrm{X}, \mathrm{e}=2.718,4.5+\mathrm{h}=\mathrm{Hmax}$, and a is a constant. In order to use Method VII it is necessary to note several printing errors of which the most important is on page 418 , i.e., $v_{h}$ should equal $c_{a n} S\left(w F_{n} F_{0}\right)+$ $c_{h_{h}} S\left(w F_{1} F_{o}\right)$. Method VIII, proposed by Staebler (19.53), involves the leastsquares solution of the parabolic equation with " $a$ " variable (not fixed at 4.5 ), i.e., $\mathrm{H}=\mathrm{a}+\mathrm{bD}-\mathrm{cD}^{2}$.

The eight methods were applied to the data from the Campus Forest used as an illustration of Method 1. The resulting regression equations and standard errors of estimate are listed in Table 1. Although the results of this single application cannot be considered as proof of the relative usefulness of the methods tested, the relative sizes of the standard errors, listed in ascending order in Table 1, are indicative thereof. 
TABLE 1

Relative ACcuracy of CuRves

\begin{tabular}{llllll}
\hline Method Originator & & Equation & \multicolumn{1}{c}{$\begin{array}{l}\text { Agg. Standard } \\
\text { Diff. Error } \\
\text { Feet Feet }\end{array}$} \\
\hline VIII & Staebler & $\mathrm{H}=18.544+9.041 \mathrm{D}-2.4417 \mathrm{D}^{2}$ & -0.1 & \pm 5.40 \\
V & Henricksen & $\mathrm{H}=-7.404+91.657 \log \mathrm{D}$ & +0.1 & \pm 5.58 \\
I & Ker & $\mathrm{H}=4.5+12.041 \mathrm{D}-0.3906 \mathrm{D}^{2}$ & -2.4 & \pm 5.61 \\
III & Smith & $\mathrm{H}=4.5+12.037 \mathrm{D}-0.3905 \mathrm{D}^{2}$ & -2.4 & \pm 5.62 \\
VI & & $\mathrm{H}=4.5+12.185 \mathrm{D}-0.4055 \mathrm{D}^{2}$ & +0.3 & \pm 5.63 \\
II & Waldie & $\mathrm{H}=4.5+11.996 \mathrm{D}-0.3935 \mathrm{D}^{2}$ & +14.7 & \pm 5.65 \\
IV & Stoffels Log H $=1.3965+0.525 \operatorname{log~D}$ & +2.0 & \pm 5.67 \\
VII & H. A. Meyer $\mathrm{H}=4.5+119\left(1-\mathrm{e}-.^{11}\right)$ & +21.9 & \pm 5.75 \\
\hline
\end{tabular}

Since the standard errors of all methods tested are acceptable, ease of application should be considered next. Methods V, VI, and VIII, involving a precise least-squares solution, suffer a serious disadvantage because of the time and equipment required for their solution. H. A. Meyer's method involving successive approximations (Method VII) is certainly most difficult to apply and does not give consistent answers. On the other hand, the approximate methods I, II, and III, requiring the expenditure of considerably less time and money, yield results that are almost equal in accuracy to precise least-square solutions. Accuracy and ease of application are compared further in Table 2.

TABLE 2

Ease of Application and Further Indication of Accuracy of Curves

\begin{tabular}{|c|c|c|c|c|c|}
\hline Method & Accuracy & $\begin{array}{l}\text { Ease of } \\
\text { Appli- } \\
\text { cation }\end{array}$ & $\begin{array}{c}\text { Accuracy } \\
\text { Plus Ease } \\
\text { of Appli- } \\
\text { cation }\end{array}$ & $\begin{array}{c}\text { H for } \\
D \underset{\text { "a" }}{=} \mathbf{O}\end{array}$ & $\begin{array}{c}\text { Squared } \\
\text { Residual } \\
\text { Weighted } \\
\text { by B A }\end{array}$ \\
\hline $\mathrm{I}$ & 3 & 3 & 6 & 4.5 & 164.12 \\
\hline II & 6 & 2 & 8 & 4.5 & 168.88 \\
\hline III & 4 & 1 & 5 & 4.5 & 164.60 \\
\hline IV & 7 & 5 & 12 & 24.92 & 178.72 \\
\hline V & 2 & 4 & 6 & -7.404 & 168.68 \\
\hline VI & 5 & 6 & 11 & 4.5 & 168.31 \\
\hline VII & 8 & 7 & 15 & 4.5 & 178.36 \\
\hline VIII & 1 & 8 & 9 & 18.54 & 164.11 \\
\hline
\end{tabular}

Table 2 provides information that should influence the choice of the method of curve fitting. When the methods are ranked on the basis of accuracy and ease of application. Method III appears most desirable. Methods I and V are similar and only slightly less desirable than Method III, but Method I has two important advantages over Method V. In Method I, "a" is fixed quite 
logically at 4.5 , and that method also avoids the use of the semi-logarithmic paper or logarithms required for Method V. Accurate freehand fitting of curves on logarithmic or semi-logarithmic paper is tedious because the residuals should not be read directly from the logarithmic scales.

Methods IV, V, and VIII, all of which permit " $a$ " to vary, are more difficult to apply and result in but slight improvement in accuracy. Moreover, one may argue that it is quite illogical to originate height-diameter curves at any point other than $\mathrm{H}=4.5, \mathrm{D}=0$.

If the appropriate method is that which provides an acceptable standard of accuracy at minimum cost, the advantages of Methods I and III are obvious. Argument for use of Methods I or III is further strengthened if squared residuals weighted by basal area are considered. The trees in the example were sorted into three equal diameter groups, and the basal area in each of these groups was calculated for the entire sample plot. The small-diameter group contained 9 per cent of the total basal area, the medium-diameter group contained 41 per cent, and the large-diameter group contained 50 per cent. When squared residuals of each group were weighted by basal area and totalled for each method, it was possible to indicate which curve had the best fit in relation to the tree volumes involved. Methods VIII, I, and III were the best in this comparison, but the gain in accuracy from use of Method VIII was insufficient to justify the additional effort expended in curve fitting by this method.

The parabolic formula, applied consistently using one of the methods described herein, compares most favorably with other mathematical methods and has a further important advantage. The mathematically descriptive constants, $b$ and $c$, or functions thereof, may be used to standardize height-diameter relationship of a species at a given age and growing on a given site. Trorey (1932) used $b$ and $c$, the parameters of the parabolic equation, to derive site-class volume tables for spruce and Douglas fir in the Interior of British Columbia. Later, Alexander (1945) applied the same method in constructing preliminary volume tables for mature timber of species growing on the British Columbia coast.

\section{The Construction of Site-Class Volume Tables}

The senior author used the parabolic formula in the construction of siteclass volume tables for immature stands of Douglas fir, western hemlock, and Sitka spruce while in the employ of the British Columbia Forest Service (1947, 1948). Data had been collected on permanent sample plots west of the Coast Range in connection with yield-plot establishment and re-measurement at fiveyear intervals in the 25-year period between 1922 and 1947. The data were analyzed to determine average stand age, site index, and parameters or functions of the calculated parabolic height-diameter equation: $b, c$, maximum height (Hmax $=4.5+b^{2} / 4 c$ ) and the d.b.h. corresponding to maximum height $\left(\mathrm{D}_{\mathrm{Hm}}=\mathrm{b} / 2 \mathrm{c}\right)$. Different combinations of the parabolic parameters with the independent variables, stand age and site index, were used to derive standard height-diameter relationships for each required age and site class. 
The best, yet most simple, method of deriving standard height-diameter curves has been described by Ker (1952b). This method makes use of the fact that there is only one parabolic curve that reaches a certain maximum at a given point on the graph, i.e., only one parabolic curve attains a given maximum height, $H \max$, at a given corresponding diameter, $D_{\mathrm{Hm}}$. As the average maximum height (Hmax) attained by a stand corresponds closely in practice to the average height of the dominant trees and is a function of its site index, the relationship between average maximum height and site index can be determined for a given species. With maximum height defined for a given age and site class, the curve form is explicitly determined by the diameter, $D_{\mathrm{Hm}}$, at which Hmax is reached. Once established for a given species, these relationships can then be used to derive the necessary sheaf of standard height-diameter curves.

The relationship between $D_{H m}$ and $H \max$ tends to be linear on semilogarithmic paper for most species. As intolerant species approach maturity, however, the relationship approaches linearity on ordinary graph paper. Thus for tolerant species a single straight-line regression of $\log D_{\mathrm{Hm}}$ on $\mathrm{Hmax}$ will suffice for all age and site classes, whereas for intolerant species two separate regressions may be required. For instance, regression equations of $D_{H_{m}}$ on Hmax determined for several important timber species in the Arrow Lakes District of British Columbia are listed in Table 3.

TABLE 3

Regression Equations of $D_{\text {Hm }}$ ON Hmax for Important Timber Species In the ARrow Lakes District of British Columbia

\begin{tabular}{|c|c|c|}
\hline Species & Age Class $^{1}$ & Regression Equation \\
\hline Aspen - Birch & All & $\log D=0.6075+0.005502 \mathrm{Hmax}$ \\
\hline Larch & All & $\log D=0.5530+0.006712 \mathrm{Hmax}$ \\
\hline Pine & $\begin{array}{l}\text { Immature } \\
\text { Mature }\end{array}$ & $\begin{aligned} \log & D=0.6450+0.006072 \text { Hmax. } \\
& D=-31.23+0.4742 \text { Hmax. }\end{aligned}$ \\
\hline Douglas fir & $\begin{array}{l}\text { Immature } \\
\text { Mature }\end{array}$ & $\begin{aligned} \log D & =0.7187+0.005596 \mathrm{Hmax} . \\
D & =-39.65+0.5659 \mathrm{Hmax} .\end{aligned}$ \\
\hline Hemlock & All & $\log D=0.7101+0.006012$ Hmax. \\
\hline Cedar & All & $\log \mathrm{D}=0.6640+0.007362 \mathrm{Hmax}$ \\
\hline
\end{tabular}

1 The immature age class includes stands up to 150 years; the mature class includes stands over 150 years of age.

For immature stands, the regression equations given in Table 3 are illustrated in Figure 1 (see page 244). Within the effective range of $\mathrm{Hmax}, \mathrm{D}_{\mathrm{Hm}}$ for a given Hmax is shown to increase with the tolerance of the species to shade. Here is a relationship that may prove to be useful not only as an objective measure of the difference in tolerance between species, but also of the change in species tolerance with stand age.

A tree-volume table applicable to a given site class may now be derived. For instance, in an 80-year-old stand of Douglas fir of site class 100, the 
FIGURE 1

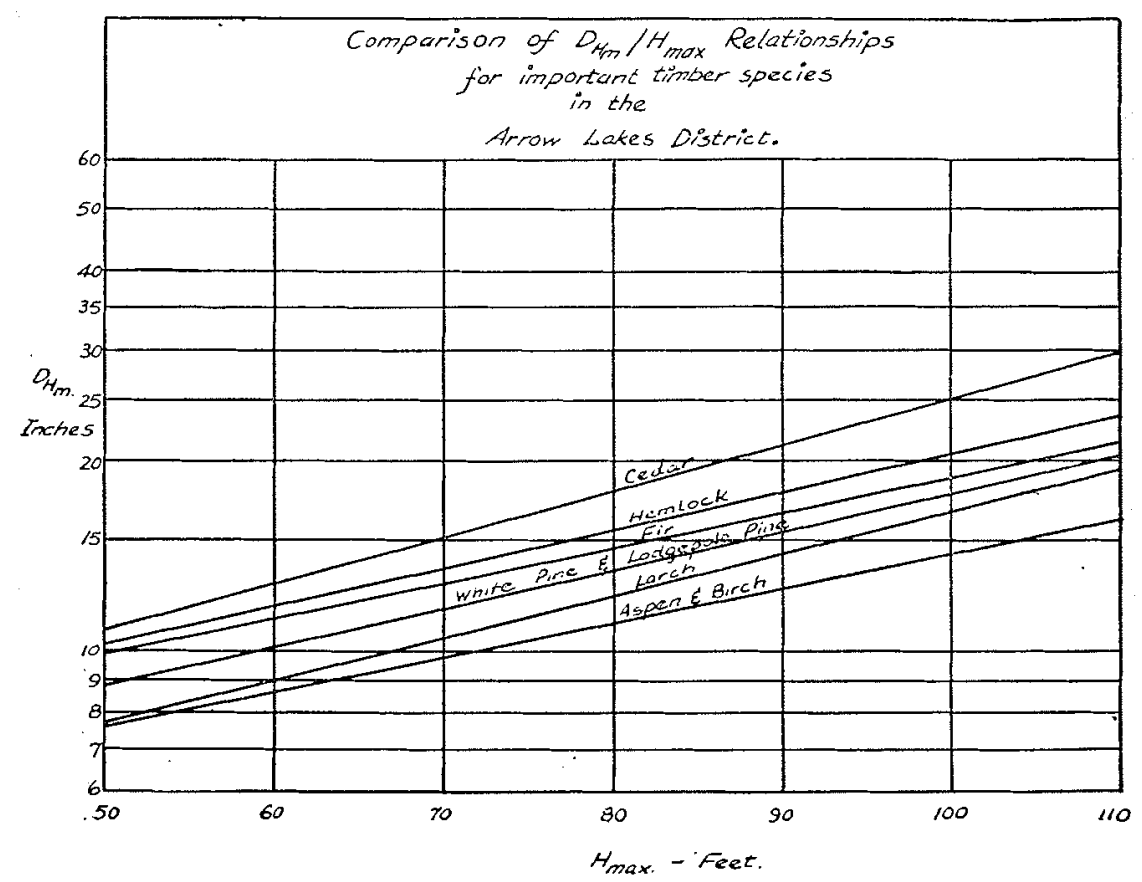

average height of dominant and codominant trees, $\overline{\mathrm{H}}_{\mathrm{DO}}$, according to McArdle and Meyer (1930, p. 12) is 91 feet. The corresponding average height of dominant trees, $\overline{\mathrm{H}}_{\mathrm{D}}$, is 96.0 feet (Ker, 1952a). From Figure 1, the corresponding $\mathrm{D}_{\mathrm{Hm}}$ for Douglas fir is $\mathbf{1 8 . 0}$ inches. The appropriate values of $\mathrm{b}$ and $\mathrm{c}$ may now be determined by solving the equations:

(1) $\mathrm{H} \max =4.5+\mathrm{b}^{2} / 4 \mathrm{c}=96$

Dividing (1) by (2):

(2) $\mathrm{D}_{\mathrm{Hm}}=\mathrm{b} / 2 \mathrm{c}=18.0$

$$
\begin{aligned}
\mathrm{b} / 2 & =91.5 / 18.0 \\
\mathrm{~b} & =10.17 \\
\mathrm{c} & =10.17 / 36.0=0.282
\end{aligned}
$$

Hence the equation of the required height-diameter relationship is $\mathrm{H}=4.5+$ $10.17 \mathrm{D}-0.282 \mathrm{D}^{2}$, and the average height of trees up to 18 inches in diameter may be estimated by solving for $\mathrm{H}$ in this equation. For trees over 18 inches in diameter the estimated height is 96 feet. In actual fact, few trees will exceed 18 inches in d.b.h. at this age on site 100 .

\section{Discussion}

The parabolic formula as applied herein is a rapid and efficient mathematical method of constructing height-diameter curves for forest stands. It is to be preferred to the free-hand method since it is entirely objective and results may 
time than is required for careful free-hand curving. Application of the parabolic formula by any of the short-cut methods is preferable to more complex mathematical solutions, on the bases of accuracy, ease of application, curve form, and the usefulness of the derived parameters in the construction of siteclass volume tables.

\section{REFERENCES}

1. ALEXANDER, J. L., 1945. A mathematical method for construction of diameter total height curves. B.C. Forest Service, File report. 3 pp.

2. BRITISH COLUMBIA FOREST SERVICE., 1947. Volume tables for second growth Douglas fir and western hemlock, Coast Region of British Columbia, by tree diameters, stand age, and site qualities. Mimeo.

LL

3. BRITISH COLUMBIA FOREST SERVICE., 1948. Volume tables for second growth Sitka spruce, British Columbia, by tree diameters, stand age, and site qualities. Mimeo.

4. BRUCE, DONALD and FRANCIS X. SCHUMACHER., 1950. Forest mensuration. McGrawHill Book Co., Inc., New York. Third edition. 483 pp.

5. HENRICKSEN, H. A., 1950. Hojde-diameter diagram med logaritmisk diameter (Heightdiameter diagram with logarithmic diameter). Dansk. Skovf. T. 35(4): 193-202.

6. KER, J. W., 1952a. An evaluation of several methods of estimating site index of immature stands. For. Chron. $28(3): 63-74$.

7. KER, J. W., 1952b. Construction of volume tables for use on the Celgar Forest Management Licence. An unpublished report submitted to Yale School of Forestry in partial fulfilment of the requirements for the degree of Doctor of Forestry. 29 pp., 9 tables.

8. KINASHI, KENKICHI., 1954. Forestry inventory by sampling methods. Reprinted from the Bulletin of the Kyushu University Forests No. 23. 153 pp.

9. McARDLE, R. E., and W. H. MEYER., 1930. The yield of Douglas fir in the Pacific Northwest. U.S. Dept. of Agr., Tech. Bul. 201. 64 pp.

10. MEYER, H. A., 1940. A mathematical expression for height curves. Jour. For, 38: 415-420.

11. STAEBLER, GEORGE R., 1954. Standard computations for permanent sample plots. Puget Sound Research Center Advisory Committee, Pacific Northwest Forest and Range Experiment Station, Portland, Oregon. 15 pp.

12. STOFFELS, A., 1950. Hoogtekromme en gemiddelde hoogte van een opstand N.B.T. 22 (4): 97-103.

13. STOFFELS, A., and J. van SOEST., 1953. Principiele vraagstukken bij proefperken. Centrale Organisatie voor Toegepast - Natuurwetenschappelijk Onderzoek, Bosbouwproefstation T.N.O. Korte mededeling nr 18. 3. Hoogteregressie. (Height regression) pp. 190-199.

14. TROREY, L. G., 1932. A mathematical method for the construction of diameter height curves based on site. For. Chron. $18(2): 3-14$. 